\title{
Infiltration of surface water through subsidence failure assessment applying electric prospecting, case Aguascalientes Valley, Mexico
}

\author{
Fernando Acuña-Lara ${ }^{1}$, Jesús Pacheco-Martinez ${ }^{2}$, Hugo Luna-Villavicencio ${ }^{1}$, \\ Martín Hernández-Marín ${ }^{2}$, and Norma González-Cervantes ${ }^{2}$ \\ ${ }^{1}$ Ciencias de los Ámbitos Antrópicos, Universidad Autónoma de Aguascalientes, Aguascalientes, Mexico \\ ${ }^{2}$ Departamento de Ingeniería Civil, Universidad Autónoma de Aguascalientes, Aguascalientes, Mexico
}

Correspondence: Fernando Acuña-Lara (arqmkx@gmail.com)

Published: 22 April 2020

\begin{abstract}
Land subsidence is an anthropogenic hazard triggered by different causes, one of them is groundwater overexploitation over aquifer systems composed for granular compressible sedimentary fill. One of the effects of this phenomenon is the generation and reactivation of ground failures, becoming risk points for aquifer pollution through the fast infiltration of contaminated water.

A system of failures and fractures has developed in the Aguascalientes valley since 1980's when groundwater overexploitation became intensive. Currently, the entire valley present regional subsidence and several ground failures have developed; many of them crossing surficial water flows and sewage pipes, thus, inducing filtering of domestic wastewater to the subsoil and increasing the environmental hazard for the aquifer system.

In this work, we present the results of a study to assess the surficial water infiltrations through a subsidence related ground failure crossing a small stream, which carries domestic wastewater. Additionally, we investigate the acquisition method of Electrical Resistivity Tomography (ERT) and the electrode placement more suitable to detect the flow of contaminated water through the studied ground failure.

To find out the potential leakage, we use electric geophysical methods, applying Schlumberger, Wenner and dipole-dipole arrangements with electrode separations from 2.5 to $10 \mathrm{~m}$ in order to explore a depth from 9 to $30 \mathrm{~m}$.

The obtained results showed that the Schlumberger configuration appears to be more helpful to detect changes in the stratigraphy toward depth, while dipole-dipole and Wenner are more suitable to detect lateral variations such as the vertical wastewater leakage in the first 6 to $8 \mathrm{~m}$ depth.

Resulted resistivity models showed that in the first $10 \mathrm{~m}$ depth, the contaminant flow follow with a vertical path through the ground failure, then, the it becomes horizontal, flowing through the more permeable soil strata. Therefore, for the studied sites, the filtration of domestic wastewater through ground failure does not represent an immediate hazard to the aquifer system. Nevertheless, ground failures crossing damaged wastewater pipes or contaminated surficial water flows in Aguascalientes Valley, could induce the infiltration of polluted water to the near surface strata, favoring a potential aquifer pollution in a long term.
\end{abstract}




\section{Introduction}

The phenomenon of subsidence is the downward and gradual vertical movement of the terrain surface, which in several cases can promote generation of terrain discontinuities (faults or fractures) and the reactivation of ancient geologic faults. In Aguascalientes Valley, located in the central part of Mexico, a process on land subsidence due to the intense pumping of groundwater has been developing since early 1980s. (Aranda-Gómez, 1989) The related surficial discontinuities spreads along the entire valley damaging constructions and infrastructure. Several of this ground discontinuities cross surficial water flows through which wastewater is conduced outside the valley (Fig. 1).

In the other side, the methods of electrical prospecting have been of help to investigate the subsoil in several problems of environmental engineering, mining, and other disciplines (Harrison-Griffiths and David-Baker, 1993; Dahlin et al., 2007; Idowu-Olayinka, 1999). Traditional electrical resistivity methods have been replaced by new techniques that result in two and three-dimensional resistivity models, and manual data acquisitions by multi-electrode and multichannel acquisitions, allowing a large efficiency in electrical prospecting works (Aizebeokhai, 2010).

There are different arrangements for the electrical resistivity method, the most commonly used are Dipole-Dipole, Wenner, and Schlumberger, each of them represents advantages and disadvantages regarding the resolution of the resulting images and the depth of exploration, therefore, it is necessary to understand the problem and focus on the results expected in order to select the appropriate arrangement (Nunes et al., 2016).

In this work we present a case of study on the potential hazard represented by wastewater filtration through subsidence related ground faults in the municipality of Jesús María Aguascalientes, México, using Electrical Resistivity Tomography (ERT). The objective of the study was assessing the surficial water infiltrations through ground failure crossing a small stream. Besides to determine the arrangement more effective to study the intrusion of wastewater through faults to the subsoil with the specific stratigraphy of Aguascalientes Valley, which consist in a sequence of alluvial and fluvial fillings (sand gravel and silt) intercalated in strata with different size grain contain and different consolidation grade (Pacheco-Martínez et al., 2013).

\section{Materials and methods}

Nine ETR measurements were taken using three electrode configurations (Dipole-Dipole, Schlumberger and Wenner) to determine which electrode configuration results in a resistivity model with more resolution to detect the ground fissure and the possible infiltrations of the wastewater and its flow through the subsoil.
Additionally, for each electrode configuration three measurements using 24 electrodes separated $2.5,5$ and $10 \mathrm{~m}$ each other were implemented, in order to determine which electrode separation is the most suitable to detect the target before mentioned.

Measurements were taken in a place, at the south of Jesús María City, which is and adjacent municipality to Aguascalientes, where a subsidence-related fault crosses a stream conducting wastewater (Fig. 1).

ERT lines were placed parallel to the wastewater stream, which is a natural channel without any type of topping on its bed to avoid infiltrations. This channel is U-shaped of $15 \mathrm{~m}$ width and $3 \mathrm{~m}$ depth.

Most of the wastewater flow through the loose filling (sand and gravel) laying in the bottom of the channel, therefore, the depth of wastewater flow that can be observed reaches just approximately $5 \mathrm{~cm}$ with an estimated flow of $0.1 \mathrm{~m}^{3} \mathrm{~min}^{-1}$.

The geophysical equipment used for this study was an automatic resitivimeter with 24 channels to connect equal number of electrodes.

\section{Results}

Field data were inverted and the resulted 2D resistivity models were elaborated with the same range of values in order to make easier their reading and interpretation. The location of the fault along the profile in Figs. 2-4 was pointed out with an arrow.

\section{Discussion of results}

Figures 2 and 3 show that the resulted resistivity models with electrode separation of 2.5 and $5 \mathrm{~m}$, report a resistive anomaly related to the location of the fault. Besides, the resistivity models allow identifying a $3-4 \mathrm{~m}$ thick horizontal surficial high resistivity layer, which has continuity along the entire profile, and it is cut by the fault. Models in these figures suggest also that with the used resolution, is no possible to detect neither the fault plane nor the path of wastewater flow.

Furthermore, Figs. 2 and 3 show that the dipole-dipole and the Schlumberger configurations result in models that allow detecting the horizontal stratigraphy, mainly the Schlumberger. In these models, the characteristic interbedding of layers of the subsoil of Aguascalientes Valley can be identified as medium-resistivity horizontal anomalies. Therefore, the Schlumberger configuration resulted more helpful to detect changes in the stratigraphy of the analyzed zones.

Figure 2 shows that the models obtained from the measurements with electrode separation of $2.5 \mathrm{~m}$ allows to detect more efficiently the surficial layer. Therefore, these models allow to detect an anomaly whose shape suggests that it is directly associated to the flow path of the wastewater. This anomaly also suggests that the wastewater flows almost ver- 


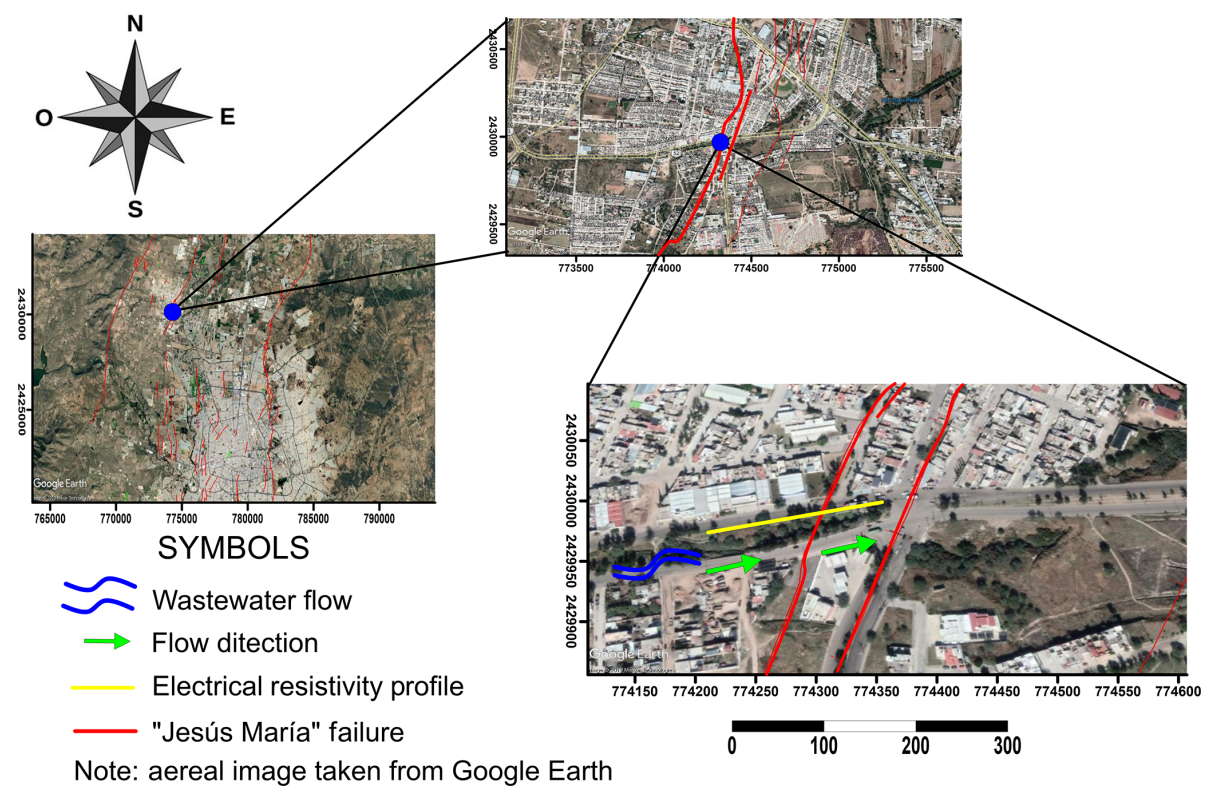

Figure 1. Location study site (ㄷ Google Earth).

(a)

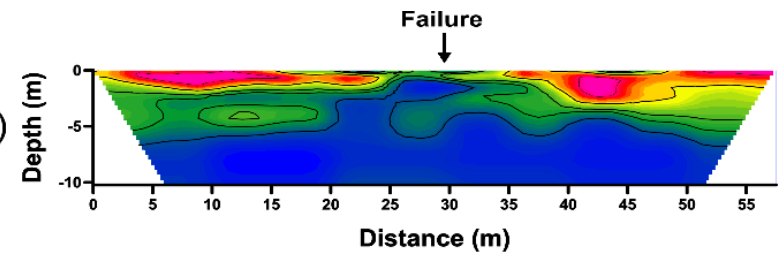

(b)

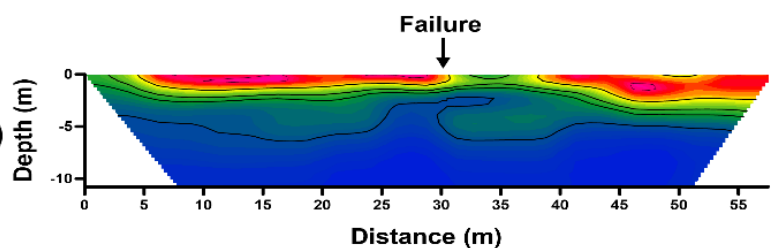

(c)

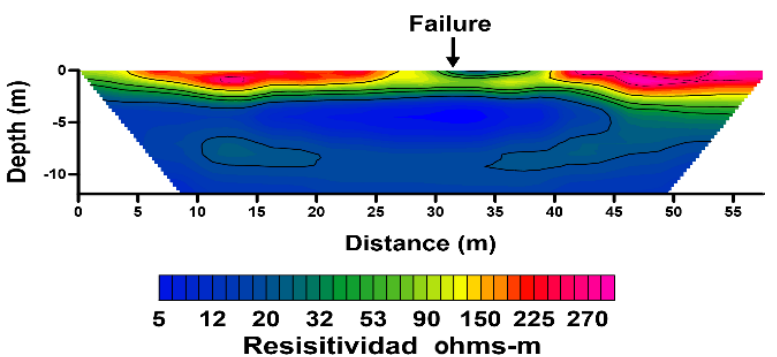

Figure 2. Profiles with $2.5 \mathrm{~m}$ opening between electrode, (a) Dipole-Dipole, (b) Wenner, (c) Schlumberger.

tically in the first $5 \mathrm{~m}$ (Fig. 5), then, it changes to a horizontal direction, probably controlled by the horizontal stratigraphy of the subsoil as reported (Hernández Marín et al., 2017).

Figure 4 presents the resistivity models elaborated from the measurements obtained using a separation between electrodes of $10 \mathrm{~m}$. In the three models, there is not a clear correlation of electrical anomalies with neither the fault location, (a)

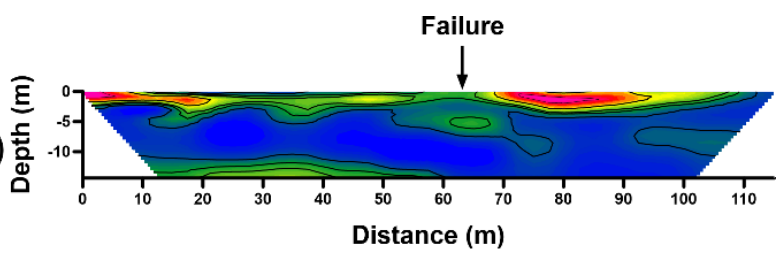

(b)
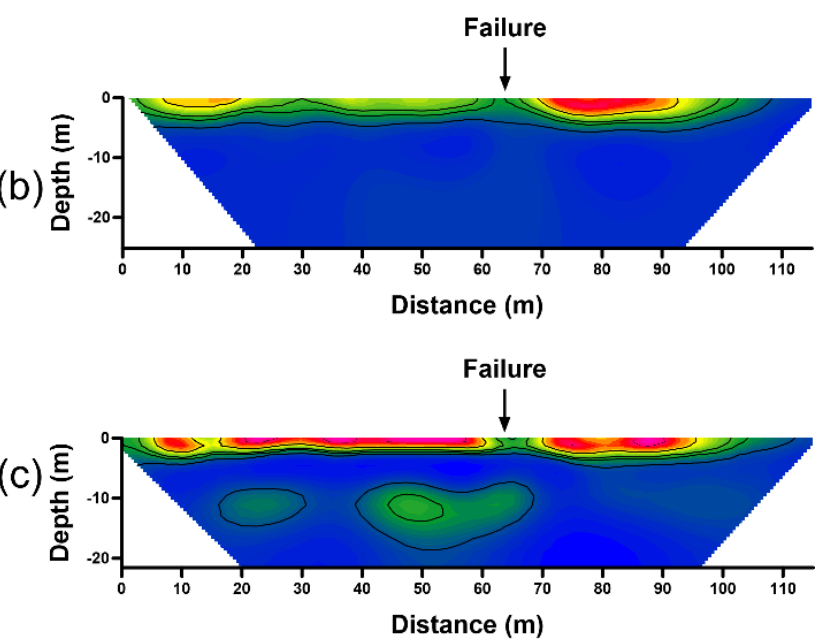

$\begin{array}{lllllllll}5 & 12 & 20 & 32 & 53 & 90 & 150 & 225 & 270\end{array}$

Resisitividad ohms-m

Figure 3. Profiles with $5 \mathrm{~m}$ opening between electrode. (a) DipoleDipole, (b) Wenner, (c) Schlumberger. 
(a)

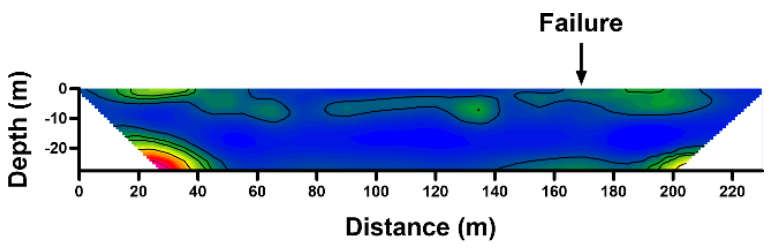

(b)

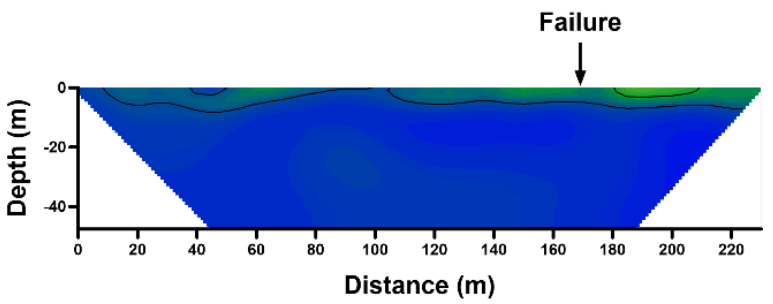

(c)

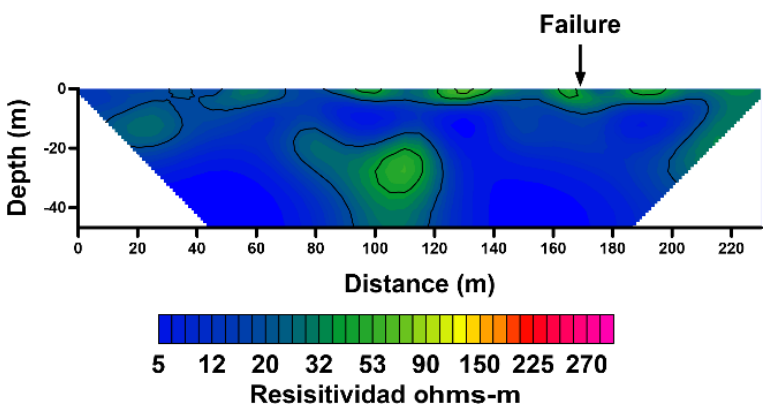

Figure 4. Profiles with $10 \mathrm{~m}$ opening between electrode. (a) Dipole-Dipole, (b) Wenner, (c) Schlumberger.

(a)

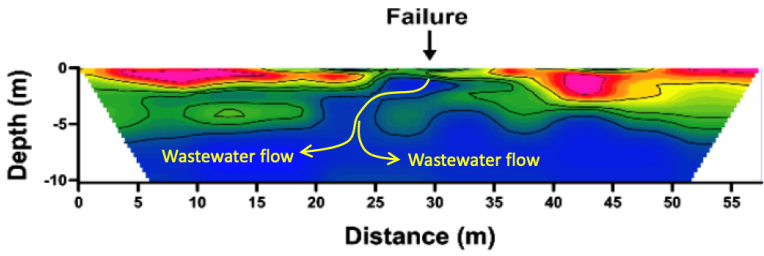

(b)

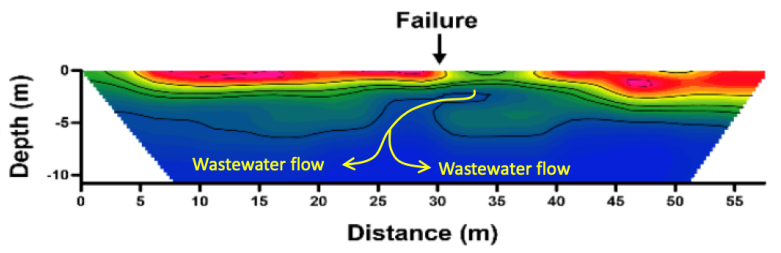

Figure 5. Interpreted lines of wastewater flow detected with ERT using an electrode spacing of $2.5 \mathrm{~m}$, and electrode configurations of (a) dipole-dipole, and (b) Wenner.

nor the flow of wastewater. Therefore, the needed resolution to detect the studied targets is achieved using an electrode separation lesser than $10 \mathrm{~m}$.

\section{Conclusions}

The method of electrical resistive tomography proved to be an effective tool to determine infiltration to the subsoil, however, results show that the greater the depth of exploration the lower the resolution.
The Schlumberger configuration appears to be more helpful to detect changes in the stratigraphy toward depth, while dipole-dipole and Wenner appears to be more suitable to detect lateral variations such as the vertical wastewater flow in the first 6 to $8 \mathrm{~m}$ depth.

The results show that the resolution needed to detect the wastewater flow path through the subsoil is using an electrode separation around $2.5 \mathrm{~m}$ and using configurations dipole-dipole and Wenner. Nevertheless, when the electrode separation is reduced, both the length of the profile and its prospecting depth decrease.

More investigation is needed to understand the water flow controlling due to the specific stratigraphy of the Aguascalientes valley, in order to determine the real aquifer contamination risk by the flow of surface water toward the subsoil through the subsidence-related faults and fractures.

Data availability. Relevant data can be provided upon request to the corresponding author.

Author contributions. FAL did the method conceptualization, data acquisition, processing, and writing. The co-authors contributed as follows: JPM reviewed processing data and writing process; HLV participated in data acquisition; and MHM and NGC reviewed the writing process as well.

Competing interests. The authors declare that they have no conflict of interest.

Special issue statement. This article is part of the special issue "TISOLS: the Tenth International Symposium On Land Subsidence - living with subsidence". It is a result of the Tenth International Symposium on Land Subsidence, Delft, the Netherlands, 17-21 May 2021

Acknowledgements. Fernando Acuña-Lara and Hugo LunaVillavicencio are thankful to CONACyT for financial support.

Financial support. This research has been supported by the Consejo Nacional de Ciencia y Tecnología (becas nacionales).

\section{References}

Aizebeokhai, A. P.: 2D and 3D geoelectrical resistivity imaging: Theory and field design, Sci. Res. Essays, 5, 3597-3599, 2010.

Aranda-Gómez, J. J.: Geología preliminar del Graben de Aguascalientes, Revista mexicana de ciencias geológicas, 8, 22-31, 1989.

Dahlin, T., Wisén, R., and Zhang, D.: 3D Effects on 2D Resistivity Imaging - Modelling and Field Surveying Results, 
Near Surface 2007 - 13th EAGE European Meeting of Environmental and Engineering Geophysics, Istanbul, Turkey, https://doi.org/10.3997/2214-4609.20146558, 2007.

Harrison-Griffiths, D. and David-Baker, R.: Two-dimensional resistivity mapping with a complex controlled array, 29, 211-226, 1993.

Hernández Marín, M., Pacheco Martínez, J., Burbey, T. J., Carreón-Freyre, D., Ochoa-González, G. H., and de LiraGómez, P.: Evaluation of subsurface infiltration and displacement in a subsidence-reactivated normal fault in the Aguascalientes Valley, Mexico, Environ. Earth Sci., 76, 812, https://doi.org/10.1007/s12665-017-7163-y, 2017.

Idowu-Olayinka, A.: Advantage of two-dimensional geoelectrical imaging for groundwater prospecting: Case study from Ira, southwestern Nigeria, J. Water Resour., 10, 55-61, 1999.
Nunes, L. M. G., Nascimento da Silva, C., and Lucena, L.: Application of the electrical resistivity method to identify karst features: Geotechnical and/or geoenvironmental implications for hydrocarbon exploration areas, Braz. J. Geophys., 34, 49-63, 2016.

Pacheco-Martínez, J., Hernández-Marín, M., Burbey, T. J., González-Cervantes, N., Ortiz-Lozano, J. Á., Zermeño-DeLeon, M. E., and Solís-Pinto, A.: Land subsidence and ground failure associated to groundwater exploitation in the Aguascalientes Valley, México, Eng. Geol., 164, 172-186, https://doi.org/10.1016/j.enggeo.2013.06.015, 2013. 